\title{
Chris Cornell, the Black Hole Sun, and the Seasonality of Suicide
}

\author{
Paul Jeffrey Schwartz \\ Cincinnati Psychoanalytic Institute, Cincinnati, $\mathrm{OH}$, USA
}

\author{
Keywords \\ Suicide - Mixed depression - Photoperiod - Seasons . \\ Latitude · Epidemiology
}

\begin{abstract}
Purpose: Seattle-inspired rock and roll superstar Chris Cornell died by suicide in May 2017. In the northern hemisphere, May represents the peak of the widely replicated but still unexplained seasonal spring rhythm in suicide. Years earlier, Cornell had suffered openly from recurrent bouts of severe depression, and his early musical lyrics do indeed suggest an enduring sensitivity to the vicissitudes of depressed and suicidal states. Cornell's most famous song, Black Hole Sun, suggests a mixed mood state, the incidence of which also peaks in the spring. The present work explores Cornell's May suicide from a chronobiologic perspective. Methods: Review of Cornell's lyrics and literature on suicide. Results: Cornell's lyrics contain clear indicators of mixed depressive and seasonal imagery, highlighting 3 fundamental axioms of suicidology: (1) the yearly suicide rhythm peaks in May in the northern hemisphere, (2) mixed depressive states are particularly lethal, and (3) the suicide risk increases dramatically when recovering from depression and mood turns mixed. Conclusions: Cornell, in his life and music, left us with a novel and important hypothesis about the spring seasonality of
\end{abstract}

suicide, namely, that the yearly suicide risk becomes maximal when winter turns to spring and there emerges a deadly mixed mood state under a May photoperiod, i.e., the suicide risk is maximal when a Black Hole Sun occurs in May. It is hoped that Cornell's legacy and sensitive hypothesis inspire research into the etiology and treatment of the spring seasonality of suicide risk and mixed mood states. Limitations: The Cornell hypothesis was formulated based in part on several speculative inferences regarding the course of his functioning just prior to his suicide.

(c) 2019 The Author(s)

Published by S. Karger AG, Basel

\section{Introduction}

In May 2017, Seattle-inspired rock-and-roll superstar Chris Cornell at age 52 years tragically and unexpectedly hanged himself after a concert performance in Detroit. Cornell had been the front man for the internationally acclaimed bands Soundgarden, Temple of the Dog, and Audioslave, where he achieved multiplatinum success and composed 13 albums in addition to the 5 additional albums he composed as a solo artist. He won 3 Grammy Awards, one of which was for his song "Black Hole Sun" for the Best Hard Rock Performance in 1995, and he was nominated numerous other times for Grammy and Gold-

\begin{tabular}{ll}
\hline KARGER & $\begin{array}{l}\text { (c) } 2019 \text { The Author(s) } \\
\text { Published by S. Karger AG, Basel }\end{array}$ \\
E-Mail karger@karger.com & $\begin{array}{l}\text { This article is licensed under the Creative Commons Attribution- } \\
\text { NonCommercial-NoDerivatives 4.0 International License (CC BY- } \\
\text { www.karger.com/nps }\end{array}$ \\
$\begin{array}{l}\text { NC-ND) (http://www.karger.com/Services/OpenAccessLicense). } \\
\text { Usage and distribution for commercial purposes as well as any dis- } \\
\text { tribution of modified material requires written permission. }\end{array}$
\end{tabular}

Paul Jeffrey Schwartz

7124 Harbour Town Dr.

West Chester, OH 45069 (USA)

E-Mail pschwartz4@ cinci.rr.com 


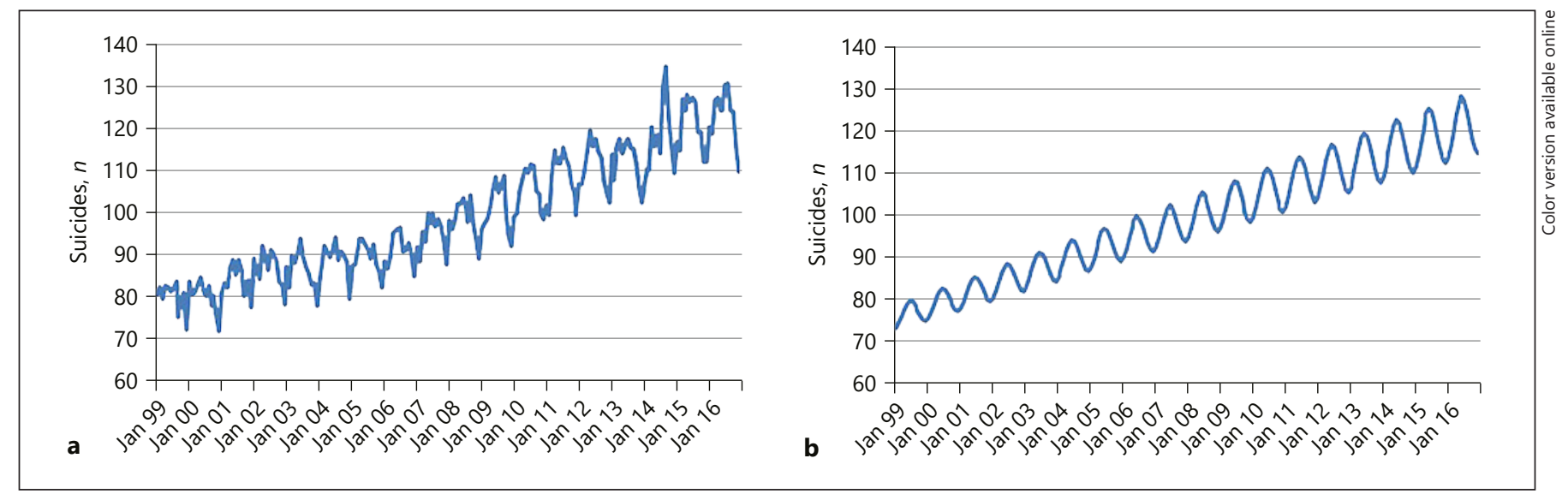

Fig. 1. a Average number of suicides per day for each month in the USA from 1999 to 2016. Note the apparent marked increase over time in the amplitude of the seasonal factor. May has the maximum number of suicides in 5 of the 18 years, whereas December has the minimum number of suicides in 15 of the 18 years. b Simplest least squares curve fit for the data in Figure 1a. The curve is described by the equation: suicides per day per month $=75.30+$ $0.22 t-(2.76+0.021 \mathrm{t}) \times \cos (2 \pi t / 12+0.006)$, where $t$ is the time (in months with January $=1,13,25 \ldots$ ) from 1 to 216 . All 5 numerical coefficients are highly significant at $p<0.0005$, including the amplifier coefficient 0.021 , which drives the linearly increasing amplitude of the seasonal suicide effect over time. en Globe Awards. He was widely regarded by his peers, fans, and critics as having one of the best rock and roll voices of our generation. The rock-and-roll world grieves over the loss of this legendary vocalist, lyricist, songwriter, and guitarist.

Cornell had in years past struggled with and talked openly about his seemingly autonomous and recurrent bouts of severe depression that were painfully intensified by his intermittent alcohol and substance abuse, although whether any formal diagnoses were ever rendered is unknown $[1,2]$. Indeed, his early lyrics do suggest a particular enduring sensitivity to the vicissitudes of depressed and suicidal states. Nevertheless, online accounts by his peers and friends suggest that he was in fact extremely happy in the months leading up to his death [3], although other accounts by his family suggest that he was having insomnia, restlessness, and agitation, and he was prescribed the benzodiazepine lorazepam for the 20 months prior to his death [4]. Cornell's autopsy report [5] revealed a lorazepam plasma level of $41 \mathrm{ng} / \mathrm{mL}$ - roughly equivalent to a 1 -h peak level following a single oral ingestion of $4 \mathrm{mg}$. This lorazepam plasma level was controversially deemed by the coroner not to have contributed to his suicide. While his suicide remains a terrible and disturbing mystery, perhaps in his life and music - his poetry - Cornell has actually revealed to us a heretofore unrecognized and important hypothesis about suicide that is worthy of our consideration.

Chris Cornell and the Seasonality of Suicide

\section{Background}

First, Cornell's heartbreaking suicide in May reminds us that May represents the month of peak suicide risk across the year in the northern hemisphere. In fact, since the original finding in 1897 [6], this seasonal spring peak in suicides has been replicated in dozens of studies in both the northern (May) and the southern (November) hemispheres [7]. The primary cause of this notorious seasonal spring peak in suicides remains unknown, but it cannot easily be explained by seasonal rhythms in either preventable (e.g., family or vocational loss, substance abuse, and access to weapons) or nonpreventable (e.g., genetics, age, and male gender) risk factors. Although some recent studies suggest that the amplitude of this seasonal rhythm in suicides may be decreasing in some countries [8], suicide data compiled by the Centers for Disease Control and Prevention indicate that this is far from the case in the USA $[9,10]$. Thus, in an analysis of the trends in US suicides from 1971 to 2000, the seasons emerged as an increasingly significant suicide risk factor over those 3 decades [9]. Further, from 1999 to 2016, there has continued to be an alarming and statistically significant increase in the amplitude of this seasonally varying suicide risk factor that exerts its maximum effect in May and that could easily account for nearly $10 \%$ of all US suicides, i.e., roughly 3,500 suicides in 2016 alone [10] (Fig. 1, 2). This increasingly significant seasonal risk factor in the USA by any account could be considered a public health epidemic.

In addition to this spring peak in suicides, there is also evidence that in both the northern and the southern hemispheres, the amplitude of this spring peak in suicides is zero near the equator (i.e., there is no seasonal variation in the constant monthly baseline risk of suicide) and steadily increases with latitude [11-14]. The cause of this latitudinal gradient in peak suicide risk also remains unknown. However, consistent with these findings is that, in both the 


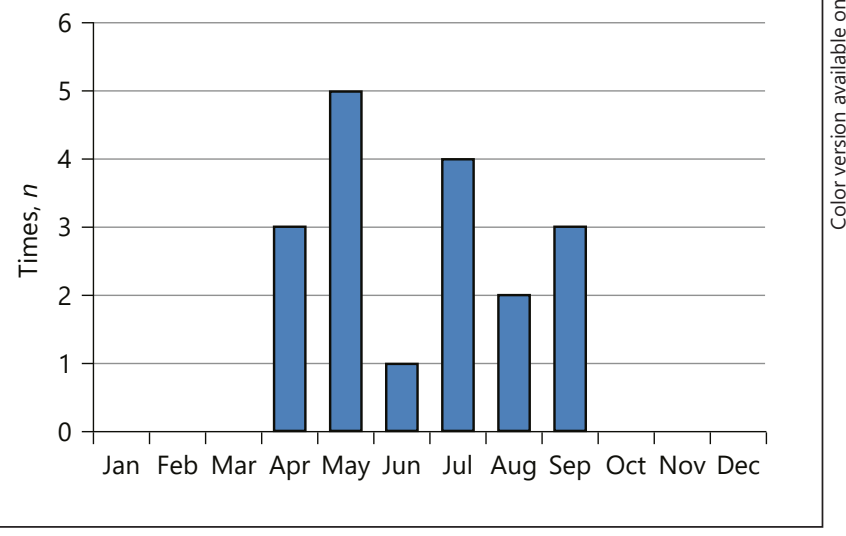

Fig. 2. Number of times that a month was the peak suicide month for a given year in the USA from 1999 to 2016.

northern and the southern hemispheres, the number of global Internet searches for "depression" also exhibits similar seasonal peaks and latitudinal gradients that consistently and forebodingly precede the spring suicide peak by several months [15]. Together, these seasonal and latitudinal gradients in suicide risk are parallel to similar seasonal and latitudinal gradients in photoperiod duration (day length) that are due to the earth's revolution around the sun and the earth's axial tilt, raising the possibility of a causal effect of photoperiod on suicide risk. Thus, Cornell's May suicide reminds us of one of the fundamental axioms of suicidology [7] - that the beautiful and alluring month of May actually carries with it the highest risk of suicide of any month in the northern hemisphere.

In addition to illuminating the month of May as the peak of the seasonal suicide risk rhythm, Cornell also illuminates important aspects about mixed depressive states, which, according to the Diagnostic and Statistical Manual-Fifth Edition (DSM-5) [16], are characterized by a full major depressive syndrome in conjunction with 3 or more manic symptoms (e.g., euphoria, insomnia, and agitation), and are well known to be associated with a greatly increased risk of suicide [7]. Controversy exists, however, regarding how many and what kind of depressive and manic symptoms may combine to constitute a nosologically and pathophysiologically meaningful entity of the mixed mood state [17-19]. Interestingly, mixed mood states are also most likely to occur in the spring, at the height of the seasonal suicide risk rhythm [20-23]. Thus, while it is unknown whether Cornell's depressions were ever formally diagnosed as mixed mood states, his description of the mixed mood state and its associated warping of one's attitude towards suicide could not be more explicit in his not-so-vaguely suicidal song "Follow My Way" from his album with the undisguised and undoubtedly mixed title "Euphoria Mourning" [24]:

Little one don't be a fool,

I'm a wreck when I look mighty.

In Euphoria I'm bruised,

In confusion next I'm lightning.

In complacence I am small,

In oblivion I'm charged.
Here, the manic symptoms of grandiosity, euphoria, and electric energy are mixed with the depressive symptoms of a damaged self, painful depressive vulnerability, and cognitive compromise, while the tension arc created by these incompatible self states results in a compelling push towards suicidal action. Without a doubt, only someone who has personally experienced a severe mixed mood state could write such graphic and sophisticated lyrics about a condition that is indeed virtually unknown to the general public. Similarly, in his deceptively romantic and soulful song "Say Hello 2 Heaven," Cornell [25] wrote:

\author{
Please, mother of mercy \\ take me from this place \\ and the long winded curses \\ I hear in my head \\ Words never listen \\ And teachers, oh, they never learn \\ But I'm warm from the candle \\ Though I feel too cold to burn.
}

Here, agony and suicidal yearning result from overwhelming self-criticism, betrayal of inner reason, and the incompatible presence of both warm and cold moods, all of which characterize the mixed depressive state. Cornell immortalizes in the extreme the agony and irreconcilable conflict of the mixed depressive state in his Grammy Award-winning song "Black Hole Sun” [26]:

Hang my head, drown my fear
Till you all just disappear
Black hole sun
Won't you come
And wash away the rain
Black hole sun
Won't you come
Won't you come.

These lyrics portray an internal psychic world during a moment of unbearable despair and on the verge of surrender to the all-powerful Black Hole Sun - the mixed (condensed) mood state comprised of both euphoric eternal salvation (sun) and fatalistic eternal destruction (black hole) - that, for better or worse, will abolish his despair. Thus, in these verses, Cornell reminds us of a second fundamental axiom of suicidology [7] - i.e., that the mixed depressive state is associated with a greatly increased risk of suicide.

But Cornell's illuminating poetry does not stop there. In his wistful song "Seasons," Cornell [27] describes the feeling of being hopelessly forsaken and helplessly left behind by the inexorable passage of seasons:

Now I want to fly above the storm

But you can't grow feathers in the rain

And the naked floor is cold as hell

The naked floor reminds me

Oh the naked floor reminds me

That I'm lost behind

Words I'll never find

And I'm left behind

As seasons roll on by.
Schwartz 
These lyrics portray how the awakening of hope, exuberance, and hypomanic grandiosity clashes with and is held hostage by cold despair - a symptom combination that also characterizes the emergence of the mixed depressive state. Thus, here, Cornell reminds us of a third fundamental axiom of suicidology [7], i.e., that the risk of suicide paradoxically increases during the process of emerging from depression - which so often occurs because of the change of seasons from winter to spring - and that this risk becomes particularly increased when one's mood ominously becomes mixed. That is, as the winter and spring seasons roll on by, while most individuals whose mood is prone to worsening in the winter will rejoice around May with the advent of spring [28], there will remain many who will become psychiatrically derailed by the change of seasons from winter to spring and will develop overwhelming and intolerable mixed depressive states around May.

\section{Discussion}

Through his life and music, Cornell exhibited and corroborated 3 separate fundamental axioms of suicidology [7]: first, May is the peak month for suicide in the northern hemisphere; second, mixed mood states carry a greatly increased risk of suicide; and third, the suicide risk is greatly increased when recovering from depression and mood turns mixed. Taken together, Cornell has left us with an inescapable, novel, important, and memorable hypothesis about suicide: the yearly suicide risk is greatest when winter turns to spring and there emerges a deadly coincidence of a mixed depressive state and a May photoperiod, i.e., the yearly suicide risk is greatest when a Black Hole Sun occurs in May. Cornell's sensitive and poetic hypothesis provides a parsimonious and compelling explanation for the well-replicated yet quite mysterious, notorious, and significant epidemiological finding of a spring peak in suicides that may account for upwards of 3,500 deaths every year in the USA alone [10].

Scores of studies over the past 100 years have examined the seasonality of suicide and most have found a late spring peak - usually in May in the northern hemisphere and in November in the southern hemisphere - in suicides in various locations around the globe. Goodwin and Jamison [7] reviewed 61 studies in the northern hemisphere and found a striking May peak in suicides and a less common, smaller bimodal October peak. Since the review of Goodwin and Jamison [7], there have been dozens of additional studies that have replicated consistent late spring peaks in suicide in nearly all of the largest datasets, including in the northern hemisphere (in those studies that reported both a monthly peak and a total $n$ for suicides), the USA (May; $n=649,843$, the present study), Japan (April; $n=501,950$ [29]), Sweden (May; $n=$

Chris Cornell and the Seasonality of Suicide
161,182 [30]), Italy (May; $n=141,180$ [31]), Finland (May; $n=96,159$ [30]), England (January; $n=92,909$ [32]), Austria (May; $n=67,741$ [33]), Mexico (May; $n=$ 64,298 [34]), Spain (July; $n=42,905$ [35]), Denmark (May; $n=37,987$ [36]), Switzerland (May/June; $n=37,518$ [37]), Norway (May; $n=20,156$ [38]), China (May; $n=$ 14,450 [39]), and Ireland (April; $n=7,899$ [40]). In the southern hemisphere, reciprocal spring peaks have been found in Australia (November; $n=57,936$ [41]), South Africa (October; $n=16,389$ [42]), and São Paulo, Brazil (November; $n=6,916$ [43]). Thus, the yearly spring peak in suicides has persisted throughout the globe for over a century since it was first identified in 1897.

Other topographic and temporal features of the seasonality of suicide have also endured in these more recent datasets. Topographically, consistent with the previously observed latitudinal gradient in suicides, recent studies have again found no seasonal variation in suicides in regions near the equator, including northern Brazil $(n=$ $31,228[14])$ and Singapore $(n=3,395$ [13]). Temporally, a smaller, second bimodal October peak in suicides in the northern hemisphere has been found in some recent studies, including in Japan (October; $n=501,950$ [29]), Sweden (October; $n=161,182$ [30]), Finland (October; $n=96,159$ [30]), and Denmark (October, $n=37,987$ [36]). This smaller second peak could be related in some way to the known second bimodal seasonal peak in the distribution of depression onsets [44]. Of note is that, in the current context, conceivably the fall peak in depression onsets would contribute to an increase in winter depressive symptoms and the ensuing spring peak in mixed depressive episodes and suicides. Thus, at the very least, any theory for the spring seasonality of suicides should ideally account for the latitudinal gradient.

With regard to the observed decrease in a number of countries over recent decades in the amplitude of the spring peak in suicides [8], several of the above mentioned more recent studies have examined this issue statistically. In the present study, there was a statistically significant and robust increase in the amplitude of the seasonal suicide rhythm over a period of 18 years (1999-2016; Fig. 1). Statistically significant increases in the amplitude of the seasonal suicide rhythm have also been found in Ireland (1980-2000) [40] and Australia (1970-1999) [41]. By contrast, the amplitude of the seasonal suicide rhythm did not change significantly in either Austria (1970-2008) [33] or China (1991-2009) [39], whereas in Norway (1969-2007) [38] and possibly Slovenia (1971-2002) [45] the amplitude decreased significantly. Clearly, the factors that contribute to these disparate temporal variations in 
the amplitude of the seasonal suicide risk factor are of great interest [8].

The present study revealed a very significant main harmonic in the US suicide data. Nevertheless conceivably, there could be multiple different single harmonics, each with a different etiology, that together produce this single main harmonic. In this regard, a number of recent studies have examined various clinical and demographic subgroupings in order to try to more precisely account for the cause of the global spring seasonality of suicide [8]. While men tend to die by suicide in far greater proportions than women ( $3: 1$ to $4: 1$ ), the seasonal spring peak is usually found in both men and women [46]. Although earlier studies have suggested that the seasonality of suicides is due to the seasonality in either "violent" (e.g., firearms, hanging, jumping) or "nonviolent" (e.g., poisoning) suicides, the significance of this categorical distinction has been not been borne out by subsequent studies [8]. Economic hardship has frequently been invoked as an explanation for the seasonality (e.g., spring brings on despair in those depressed individuals for whom their arduous springtime agricultural work might suddenly feel overwhelming) [6, 47]. Related to the economic hypothesis, a number of studies have examined rural versus urban differences in the seasonality of suicide, and individuals living in rural environments have exhibited greater spring peaks in suicide as compared to individuals living in urban environments. This rural increase has been found in France [6], Hungary [48], New Zealand [49], Sweden [49], and Austria [50], but not in Mexico [34]. The possibility that differences in sunlight and artificial light exposure might account for these urban-rural differences has not previously been considered [51, 52]. A number of studies have consistently found that, compared to individuals without an established psychiatric diagnosis, the spring seasonality of suicide is more pronounced in individuals with an established psychiatric diagnosis $[53,54]$, especially in individuals with a history of mood disorders $[36,55]$. In short, whether there are multiple distinct seasonalities (harmonics) associated with various subgroupings that contribute to the main spring peak in suicides remains an open question for future research.

Returning to the global findings of seasonal spring and latitudinal gradients in suicide, variations in the amount of sunlight and/or the ambient temperature have for a long time been considered as the most likely causes. Indeed, because the seasonal and global variations in these meteorological factors are so obviously congruent with the seasonal and global epidemiology of suicide, a great effort has been expended trying to factor out these "trivial" seasonal meteorological associations while looking for the more "valid" underlying proximate causes of the seasonal spring suicide risk. Thus, after removal of seasonal sunshine components, 2 studies have managed to find weak, but significant, positive correlations between the suicide risk and the amount of sunshine on the day of the suicide (i.e., more sunshine, greater risk) [56, 57]. Similar considerations apply to the general lack of a robust association found between variations in the amplitudes of the seasonal spring suicide peaks and ambient temperatures [58], although again several positive associations have been found [29,59]. Notably, consistent with the Cornell hypothesis of an inciting role of winter depressive symptoms in the genesis of a spring mixed depressive suicidal state, increasingly cloudy winters have been associated with an increasingly elevated suicide risk the following spring [60]. Thus, perhaps it is time to consider that the overarching photoperiod may not only be the most obvious correlate, but it may also be the most likely underlying cause of the main harmonic driving the seasonality of mixed mood states and the seasonal and latitudinal gradients of suicide.

Implicit in the Cornell hypothesis is that the deadly mixed mood state that evolves in the spring and that accounts for the May suicide peak is of the depressive mixed state variety and not the manic mixed state variety. This must be so not only because of the congruent and robust epidemiologic contours (i.e., seasonality and latitudinal gradient) of both winter depression and spring suicide but also because there is no evidence that Cornell ever exhibited frank mania. In addition, given the very high prevalence of depression compared to mania, mixed depressive episodes are certainly far more common than mixed manic episodes [18] and thus only mixed depressive episodes can account for the robust May peak in suicides. Nevertheless, many if not most researchers would agree that there is a continuum from unipolar depression to mixed depression to mixed mania to mania [61], such that the pathophysiology of mixed depression is likely related to that of both unipolar depression and bipolar disorder. What else has Cornell taught us about the psychology and biology of the seasonality of mixed depressive states and suicide risk?

With regard to the psychology of mixed depressive states and suicide risk, Cornell is rather clear that the intensity of suicidal ideation in the mixed depressive state is related to the degree to which there is tension or conflict between the depressive (e.g., fatalistic) and manic (e.g., euphoric/grandiose) polar elements of mood. As near as
Schwartz 
can be determined, this clinically important phenomenon regarding the association between the severity of mood conflict and suicidal ideation in mixed mood states has not previously been described. However, consistent with this observation, a number of studies have found associations between the presence and extent of certain manic symptoms (e.g., psychomotor agitation and impulsivity) and suicidal ideation in patients with major depression with mixed depressive states [62-64]. What exactly it is about the presence of the conflicting mixed moods that accentuates suicidal ideation is not entirely clear, although Cornell seems to suggest that it is the hopeless futility over the irreconcilable conflict between the extreme polar opposite moods. Conceivably, the intensity of suicidal ideation in mixed states is proportional to the area of contact between the specific symptoms of 2 incompatible surfaces - depression and mania. In this regard, one wonders whether the term "mixed" mood state might actually be somewhat of a misnomer, and whether the term "unmixed" or "immiscible" mood state might not be more apt, as the polar opposite moods in the mixed mood state do not mix at all, much like the separation between oil and water. In any case, given the very distinct timing of the spring peak in suicidal mixed mood states, one is tempted to attribute this heightened springtime conflict between polar opposite moods to some kind of pathological transitional state between winter and summer modes of mood and energy regulation (i.e., depression vs. mania). Relevant to this hypothesis of transitions from winter to spring is that many, but not all, studies have found summer peaks in the incidence of mania [reviewed in 65].

With regard to the biology of the seasonal spring mixed depressive state and suicide risk, Cornell is rather clear that it is the transition from winter to spring and the ensuing emergence of the mixed mood state that produce lethality. Thus, the psychobiology of the winter-to-spring seasonal change is of great interest. One way to avoid the obvious confounding associational effects between the spring suicide risk and the seasonally varying photoperiod would be to simply study the direct effect of the photoperiod on the biological structures that are clearly regulated by the photoperiod. In this regard, seasonal changes in photoperiod duration have been associated with abnormally exaggerated seasonal changes in the duration of nocturnal pineal melatonin secretion in patients who exhibit abnormal seasonal changes in mood, energy, and sleep [66]. These photoperiod-induced exaggerated seasonal changes in the duration of pineal melatonin secretion are associated with

Chris Cornell and the Seasonality of Suicide exaggerated seasonal changes in the circadian interval between the evening (E) and morning $(\mathrm{M})$ circadian oscillators in the suprachiasmatic nucleus that track dusk and dawn, respectively, and that control the onset and offset of both sleep and melatonin secretion [67]. In patients with recurrent winter depression [68], the expansion between $\mathrm{E}$ and $\mathrm{M}$ in the long nights of winter is associated with depression (deflated mood), whereas the contraction between $\mathrm{E}$ and $\mathrm{M}$ in the short nights of summer is associated with hypomania (inflated mood). Consistent with this formulation, Wehr [69] found convincing direct clinical evidence that rapid and alternating changes in the phase relationship between $\mathrm{E}$ and $\mathrm{M}$ were tightly coupled with corresponding rapid and alternating changes in manic and depressive cycles in patients with rapidly cycling bipolar disorder. These alternations between the coupling of $\mathrm{E}$ and $\mathrm{M}$ in rapidly cyclingbipolar disordermayreflect dissociated components of the master circadian clock in the suprachiasmatic nucleus that are in metastable phase relationships with one another [69]. Currently, there is no chronobiologic model specifically for the mixed mood state, although one can certainly imagine multiply dissociated components of the suprachiasmatic nucleus pathologically and simultaneously splitting mood into is polar components that might be reflected in a multimodal 24 -h plasma melatonin profile [70]. Thus, studies of the effects of the photoperiod on E, M, mood, and sleep in patients who develop mixed mood states during the transition from winter to spring are of interest.

From another perspective, seasonally depressed patients, along with seasonal changes in the interval between $\mathrm{E}$ and $\mathrm{M}$, also exhibit abnormal seasonal changes in the level of core body temperature during sleep [71] that could reflect abnormal seasonal changes in either the amplitude of the circadian pacemaker or the energy-regulating function of the central thermostat $[72,73]$. Of note is that this seasonally responsive central thermostat governs the sensitivity of certain brain dopamine- $2\left(\mathrm{D}_{2}\right)$ receptors [74], which are the therapeutic mood-stabilizing neuroreceptor targets for the atypical antipsychotic medications that are effective for mixed depressive states [17]. Further, genetic variations affecting central $\mathrm{D}_{2}$ receptor function regulate variations in habitual sleep duration in humans [75], while striatal extracellular dopamine concentrations and striatal $\mathrm{D}_{2}$ receptors modulate the activity-rest ratio in mice [76]. Thus, studies of the thermostat's regulation of central $\mathrm{D}_{2}$ receptors, dopamine, mood, arousal, and E-M and sleep duration in spring mixed depressive states become of interest [77].

Neuropsychobiology 2018/2019;78:38-47 
From yet another perspective with regard to mood regulation, habitual short sleepers tend to be more dispositionally hypomanic than habitual long sleepers, who tend to be more depressed $[78,79]$. Consistent with these findings, hypomanic (inflated mood) habitual short sleepers have relatively contracted E-M intervals compared to depressed (deflated mood) habitual long sleepers [80]. These observations indicate that the sleep homeostat and its functional connections with the $\mathrm{E}$ and $\mathrm{M}$ oscillators regulate mood pressure and are consistent with circadian forced desynchrony studies in which the circadian rhythms are experimentally dissociated from the sleep-wake rhythms and that have demonstrated a complex and decidedly "mixed" interaction between the sleep homeostat and the circadian pacemaker in regulating subjective arousal [81] and mood [82]. What kind of studies might provide a way forward in trying to understand Cornell's hypothesis of the spring seasonality of mixed mood states and suicide?

First, with regard to the hypothesized role of seasonal changes in the photoperiod-tracking system (E-M phase relationship) in suicidal mixed mood states, studies could examine the 24 -h profile of melatonin secretion in patients who present with mixed mood states compared to seasonally matched healthy controls. Such a study could clarify whether E-M contraction, expansion, and/or dissociation exists in patients with mixed mood states. Conceivably, a second study - which could follow the first melatonin study - could investigate the role of $\mathrm{D}_{2}$ receptors and the central thermostat in the regulation of E-M and sleep duration, arousal, and mood. This $\mathrm{D}_{2}$ receptor investigation could also be repeated after an atypical antipsychotic medication treatment trial to further investigate the role of $\mathrm{D}_{2}$ receptors in regulating these functions in the mixed mood state and recovery. In addition, for selected patients, the first melatonin study could instead be followed by and repeated after a longitudinal case therapeutic study of extended darkness (e.g., 10-h days and 14-h nights); this approach has been found to be so promising with rapidly cycling bipolar patients [69]. Finally, in order to dissect the cross-sectional circadian and homeostatic influences on mood and sleep in patients with mixed mood disorders, carefully conducted studies using the forced desynchrony paradigm could be completed on patients with mixed mood states throughout the year.

With regard to the detection, prevention, and treatment of individuals with suicidal mixed mood states, an important effort would be to heighten the awareness of clinicians to the distinction between unipolar depression and mixed depression, which would be of particular ur- gency when mixed mood episodes occur in the spring. Given that treatments for mixed depression versus unipolar depression are very different and may even be dangerous if misapplied [17], raising the awareness of clinicians and patients regarding this diagnostic distinction remains an ongoing and crucial matter. Also in this regard, it would be important to encourage the use a reliable and valid self-administered rating scale [83] for the better detection of mixed mood states, and to more fully explore the degree of mood conflict and suicidal ideation in patients with mixed mood episodes. Finally, it seems important to raise physician awareness regarding the potential risk of prescribing benzodiazepines to patients with mood disorders who have a history of suicidal ideation or attempts, as the currently available evidence suggests that chronic treatment with benzodiazepines can increase the suicidal risk [84-86].

\section{Limitations}

The public record over the past 3 decades of Cornell's lyrics and his many interviews leaves no doubt that Cornell suffered intermittently from severe depression, mixed depressive states, and substance abuse during the first half of his adulthood and music career. The record also indicates that he had a very long interval of euthymia, abstinence, and superior functioning during the second half of his adulthood and music career until a number of months before his death. In the present context, it must be acknowledged that the hypothesis regarding the role of seasonality and the springtime emergence of a mixed mood state in Cornell's suicide remains somewhat speculative in the absence of a firsthand record of the longitudinal course of his functioning and any psychiatric evaluations and treatments. For example, it would be of interest to know whether Cornell actually exhibited any mood susceptibility - even if only occasionally - to the change of seasons such as he wrote so compellingly about in his song "Seasons" [27]. Importantly, Cornell's inferred mixed depressive state at the time of his death was based upon the concurrent and polar opposite observations of those who were closest to him and not upon any direct evaluation by a professional. Thus, in summary, while the combination of photoperiod changes, winter depressive symptoms, springtime mixed depressive states, and May suicides provides a parsimonious explanation for Cornell's lyrics, his history of depression, and the timing of his suicide, the hypothesis that he inspired, while internally consistent, ultimately remains somewhat speculative.
Schwartz 


\section{Concluding Remarks}

It is well known that many of our time-honored and most revered artists have been exquisitely sensitive to both their external (i.e., outside) and their internal (i.e., intrapsychic) worlds and, as such, they have been uniquely positioned to inform us about hidden and undiscovered aspects of our universe. Cornell likely suffered the tragic burden of having a serious, intermittent, mixed mood disorder that rendered him frequently suicidal, especially during the first half of his adulthood and music career. At the same time, his perceptive sensitivity to his mood fluctuations provided the fodder for not only some of his most famous visceral music and lyrics but also the novel hypothesis of the present investigation regarding the important phenomenon of the spring seasonality of suicide. Whether Cornell's transcendent hypothesis about mixed depressive states and the spring seasonality of suicide - inspired as it were by his life and music - can explain Cornell's suicide in May 2017 will probably forever remain unknown. Just 2 months before his death and just as winter had turned to spring, Cornell reached out to a friend in an email indicating that he had "relapsed" [4]. Could he have been referring in part to his dreaded relapse into darkness that complicated his nascent and buoyant recovery from depression that many years earlier [2] had inspired one of his most classic signature songs, i.e., "Fell on Black Days" [87]:

Whatsoever I've feared has come to life Whatsoever I've fought off became my life

Just when everyday seemed to greet me with a smile

Sunspots have faded and now I'm doing time

Now I'm doing time

'Cause I've fell on black days

I've fell on black days, black days.
Hopefully, Cornell's novel hypothesis about suicide will motivate research into this very common, global, and all-too-often fatal seasonal disorder that likely involves a faulty interaction between seasonal [88] and circadian [89] mechanisms.

\section{Acknowledgment}

The author acknowledges the inspiring and monumental legacy of the late Chris Cornell.

\section{Statement of Ethics}

The author has never had any personal or professional relationship with Chris Cornell, whose life and lyrics are instantly and widely recognizable worldwide. As such, all of the data contained in this report were obtained exclusively from freely and publically available sources (e.g., record albums, Internet interviews, and news reports). This study therefore did not require approval from an ethics committee because it did not involve any direct clinical contact or human experimentation or disclosure of any confidential patient data or personally protected health information.

\section{Disclosure Statement}

The author reports no other conflicts of interest.

\section{Funding Sources}

This research received no specific grant from any funding agency or the commercial or not-for-profit sector.

\section{References}

1 Runtagh J [Internet]. Chris Cornell: from drugs at 13 to one of the most influential voices of the Seattle scene. Available from: https:// people.com/music/chris-cornell-life-influential-seattle-scene/.

2 Grow K [Internet]. Soundgarden's Chris Cornell on "Superunknown," depression, and Kurt Cobain. Available from: https://www. rollingstone.com/music/music-features/ soundgardens-chris-cornell-on-superunknown-depression-and-kurt-cobain$119623 /$.

Chris Cornell and the Seasonality of Suicide
3 Richter K [Internet]. Chris Cornell was in "great spirits" shortly before his death his friends say: "It's a complete shock." Available from: https://people.com/music/chris-cornell-great-spirits-before-death/.

4 Roberts R [Internet]. Chris Cornell widow says his battle with addiction led to his suicide. "He loved his life." Available from: https://www.youtube.com/watch? $\mathrm{v}=\mathrm{QMPz}-$ ePW6AXE

5 Brown T [Internet]. Autopsy report: Chris Cornell. Available from: https://www.scribd. com/document/350206037/Autopsy-ReportChris-Cornell.
6 Durkheim E. Suicide. A Study in Sociology. New York (NY): The Free Press; 1951.

7 Goodwin F, Jamison K. Manic-depressive illness. New York: Oxford University Press; 1990.

8 Ajdacic-Gross V, Bopp M, Ring M, Gutzwiller F, Rossler W. Seasonality in suicide-a review and search of new concepts for explaining the heterogeneous phenomena. Soc Sci Med. 2010 Aug;71(4):657-66.

9 Bridges FS, Yip PS, Yang KC. Seasonal changes in suicide in the United States, 1971 to 2000. Percept Mot Skills. 2005 Jun;100(3 Pt 2): 920-4. 
10 National Center for Health Statistics [Internet]. Underlying cause of death, 1999-2016. CDC WONDER online database (USA) [cited 2018 May 18]. Available from: http://wonder.cdc.gov/ucd-icd10.html.

11 Terao T, Soeda S, Yoshimura R, Nakamura J, Iwata N. Effect of latitude on suicide rates in Japan. Lancet. 2002 Dec;360(9348):1892.

12 Heerlein A, Valeria C, Medina B. Seasonal variation in suicidal deaths in Chile: its relationship to latitude. Psychopathology. 2006;39(2):75-9.

13 Parker G, Gao F, Machin D. Seasonality of suicide in Singapore: data from the equator. Psychol Med. 2001 Apr;31(3):549-53.

14 Benedito-Silva AA, Pires ML, Calil HM. Seasonal variation of suicide in Brazil. Chronobiol Int. 2007;24(4):727-37.

15 Yang AC, Huang NE, Peng CK, Tsai SJ. Do seasons have an influence on the incidence of depression? The use of an Internet search engine query as a proxy of human affect. PLoS One. 2010 Oct 28;5(10):e13728.

16 American Psychiatric Association. Diagnostic and Statistical Manual of Mental Disorders. 5th ed. Arlington (VA): American Psychiatric Association; 2013.

17 Stahl SM. Mixed-up about how to diagnose and treat mixed features in major depressive episodes. CNS Spectr. 2017 Apr;22(2):111-5.

18 Vieta E, Valentí M. Mixed states in DSM-5: implications for clinical care, education, and research. J Affect Disord. 2013 May; 148(1): 28-36.

19 Malhi GS, Byrow Y, Outhred T, Fritz K. Exclusion of overlapping symptoms in DSM-5 mixed features specifier: heuristic diagnostic and treatment implications. CNS Spectr. 2017 Apr;22(2):126-33.

20 Lee HC, Tsai SY, Lin HC. Seasonal variations in bipolar disorder admissions and the association with climate: a population-based study. J Affect Disord. 2007 Jan;97(1-3):61-9.

21 Yang AC, Yang CH, Hong CJ, Liou YJ, Shia $B C$, Peng CK, et al. Effects of age, sex, index admission, and predominant polarity on the seasonality of acute admissions for bipolar disorder: a population-based study. Chronobiol Int. 2013 May;30(4):478-85.

22 Geoffroy PA, Bellivier F, Scott J, Etain B. Seasonality and bipolar disorder: a systematic review, from admission rates to seasonality of symptoms. J Affect Disord. 2014 Oct; 168: 210-23.

23 Dominiak M, Swiecicki L, Rybakowski J. Psychiatric hospitalizations for affective disorders in Warsaw, Poland: effect of season and intensity of sunlight. Psychiatry Res. 2015 Sep; 229(1-2):287-94.

24 Cornell C. Follow My Way: Euphoria Mourning [album]. Santa Monica (CA): Interscope Records; 1999.

25 Cornell C. Say Hello 2 Heaven: Temple of the Dog [album]. Santa Monica (CA): A\&M Records; 1991.

26 Cornell C. Black Hole Sun: Superunknown [album]. Santa Monica (CA): A\&M Records; 1994.
27 Cornell C. Seasons: Singles [album]. Beverly Hills (CA): Epic Records; 1992.

28 Schwartz PJ, Brown C, Wehr TA, et al. Winter-seasonal affective disorder: a follow up study of the first 59 patients of the NIMH seasonal studies program. Am J Psychiatry. 1996; 153:1028-36.

29 Likhvar V, Honda Y, Ono M. Relation between temperature and suicide mortality in Japan in the presence of other confounding factors using time-series analysis with a semiparametric approach. Environ Health Prev Med. 2011 Jan;16(1):36-43.

30 Holopainen J, Helama S, Björkenstam C, Partonen T. Variation and seasonal patterns of suicide mortality in Finland and Sweden since the 1750s. Environ Health Prev Med. 2013 Nov;18(6):494-501.

31 Preti A, Lentini G. Forecast models for suicide: time-series analysis with data from Italy. Chronobiol Int. 2016;33(9):1235-46.

32 Cavanagh B, Ibrahim S, Roscoe A, Bickley H, While $\mathrm{D}$, Windfuhr $\mathrm{K}$, et al. The timing of general population and patient suicide in England, 1997-2012. J Affect Disord. 2016 Jun; 197:175-81.

33 Nader IW, Pietschnig J, Niederkrotenthaler T, Kapusta ND, Sonneck G, Voracek M. Suicide seasonality: complex demodulation as a novel approach in epidemiologic analysis. PLoS One. 2011 Feb;6(2):e17413.

34 Fernández-Niño JA, Astudillo-García CI, Bojorquez-Chapela I, Morales-Carmona E, Montoya-Rodriguez AA, Palacio-Mejia LS. The Mexican cycle of suicide: a national analysis of seasonality, 2000-2013. PLoS One. 2016 Jan;11(1):e0146495.

35 Santurtún M, Santurtún A, Zarrabeitia MT. Does the environment affect suicide rates in Spain? A spatiotemporal analysis. Rev Psiquiatr Salud Ment. 2018 Oct-Dec;11(4): 192-8.

36 Postolache TT, Mortensen PB, Tonelli LH, Jiao X, Frangakis C, Soriano JJ, et al. Seasonal spring peaks of suicide in victims with and without prior history of hospitalization for mood disorders. J Affect Disord. 2010 Feb; 121(1-2):88-93.

37 Ajdacic-Gross V, Wang J, Bopp M, Eich D, Rössler W, Gutzwiller F. Are seasonalities in suicide dependent on suicide methods? A reappraisal. Soc Sci Med. 2003 Oct;57(7):1173-81.

38 Bramness JG, Walby FA, Morken G, Røislien J. Analyzing seasonal variations in suicide with Fourier Poisson time-series regression: a registry-based study from Norway, 19692007. Am J Epidemiol. 2015 Aug;182(3):24454.

39 Sun J, Guo X, Ma J, Zhang J, Jia C, Xu A. Seasonality of suicide in Shandong China, 19912009: associations with gender, age, area and methods of suicide. J Affect Disord. 2011 Dec; 135(1-3):258-66.

40 Casey P, Gemmell I, Hiroeh U, Fulwood C. Seasonal and socio-demographic predictors of suicide in Ireland: a 22 year study. J Affect Disord. 2012 Feb;136(3):862-7.
41 Rock D, Greenberg DM, Hallmayer JF. Increasing seasonality of suicide in Australia 1970-1999. Psychiatry Res. 2003 Aug;120(1): 43-51.

42 Flisher AJ, Parry CD, Bradshaw D, Juritz JM. Seasonal variation of suicide in South Africa. Psychiatry Res. 1997 Jan;66(1):13-22.

43 Bando DH, Volpe FM. Seasonal variation of suicide in the city of São Paulo, Brazil, 19962010. Crisis. 2014;35(1):5-9.

44 Wehr TA. Seasonal affective disorders: a historical overview. In: Rosenthal NE, Blehar MC, editors. Seasonal affective disorders and phototherapy. New York: Guilford Press; 1987.

45 Oravecz R, Rocchi MB, Sisti D, Zorko M, Marusic A, Preti A. Changes in the seasonality of suicides over time in Slovenia, 1971 to 2002. J Affect Disord. 2006 Oct;95(1-3):13540.

46 Micciolo R, Zimmermann-Tansella C, Williams $\mathrm{P}$, Tansella M. Seasonal variation in suicide: is there a sex difference? Psychol Med. 1989 Feb;19(1):199-203.

47 Christodoulou C, Douzenis A, Papadopoulos FC, Papadopoulou A, Bouras G, Gournellis R, et al. Suicide and seasonality. Acta Psychiatr Scand. 2012 Feb;125(2):127-46.

48 Rihmer Z, Gonda X, Kapitany B, Dome P. Suicide in Hungary-epidemiological and clinical perspectives. Ann Gen Psychiatry. 2013 Jun;12(1):21.

49 Granberg D, Westerberg C. On abandoning life when it is least difficult. Soc Biol. 1999; 46(1-2):154-62.

50 Kapusta ND, Zorman A, Etzersdorfer E, Ponocny-Seliger E, Jandl-Jager E, Sonneck G. Rural-urban differences in Austrian suicides. Soc Psychiatry Psychiatr Epidemiol. 2008 Apr;43(4):311-8.

51 Carvalho FG, Hidalgo MP, Levandovski R. Differences in circadian patterns between rural and urban populations: an epidemiological study in countryside. Chronobiol Int. 2014 Apr;31(3):442-9.

52 Wehr TA, Giesen HA, Moul DE, Turner EH, Schwartz PJ. Suppression of men's responses to seasonal changes in day length by modern artificial lighting. Am J Physiol. 1995 Jul; 269(1 Pt 2):R173-8.

53 Rocchi MB, Sisti D, Miotto P, Preti A. Seasonality of suicide: relationship with the reason for suicide. Neuropsychobiology. 2007;56(23):86-92.

54 Yip PS, Yang KC, Qin P. Seasonality of suicides with and without psychiatric illness in Denmark. J Affect Disord. 2006 Nov;96(1-2): 117-21.

55 Reutfors J, Osby U, Ekbom A, Nordström P, Jokinen J, Papadopoulos FC. Seasonality of suicide in Sweden: relationship with psychiatric disorder. J Affect Disord. 2009 Dec;119(13):59-65. 
56 Seregi B, Kapitány B, Maróti-Agóts Á, Rihmer Z, Gonda X, Döme P. Weak associations between the daily number of suicide cases and amount of daily sunlight. Prog Neuropsychopharmacol Biol Psychiatry. 2017 Feb;73:41-8.

57 Vyssoki B, Kapusta ND, Praschak-Rieder N, Dorffner G, Willeit M. Direct effect of sunshine on suicide. JAMA Psychiatry. 2014 Nov; 71(11):1231-7.

58 Ajdacic-Gross V, Lauber C, Sansossio R, Bopp M, Eich D, Gostynski M, et al. Seasonal associations between weather conditions and suicide-evidence against a classic hypothesis. Am J Epidemiol. 2007 Mar;165(5):561-9.

59 Souêtre E, Wehr TA, Douillet P, Darcourt G. Influence of environmental factors on suicidal behavior. Psychiatry Res. 1990 Jun;32(3): 253-63.

60 Ruuhela R, Hiltunen L, Venäläinen A, Pirinen $\mathrm{P}$, Partonen T. Climate impact on suicide rates in Finland from 1971 to 2003. Int J Biometeorol. 2009 Mar;53(2):167-75.

61 Swann AC. Mixed features: evolution of the concept, past and current definitions, and future prospects. CNS Spectr. 2017 Apr;22(2): 161-9.

62 Akiskal HS, Benazzi F, Perugi G, Rihmer Z. Agitated "unipolar" depression re-conceptualized as a depressive mixed state: implications for the antidepressant-suicide controversy. J Affect Disord. 2005 Apr;85(3):24558.

63 Perugi G, Angst J, Azorin JM, Bowden CL, Mosolov S, Reis J, et al.; BRIDGE-II-Mix Study Group. Mixed features in patients with a major depressive episode: the BRIDGE-IIMIX study. J Clin Psychiatry. 2015 Mar; 76(3):e351-8.

64 Popovic D, Vieta E, Azorin JM, Angst J, Bowden CL, Mosolov S, et al. Suicide attempts in major depressive episode: evidence from the BRIDGE-II-Mix study. Bipolar Disord. 2015 Nov; 17(7):795-803.

65 Aguglia A, Borsotti A, Maina G. Bipolar disorders: is there an influence of seasonality or photoperiod? Braz J Psychiatry. 2018 JanMar;40(1):6-11.

66 Wehr TA, Duncan WC Jr, Sher L, Aeschbach D, Schwartz PJ, Turner EH, et al. A circadian signal of change of season in patients with seasonal affective disorder. Arch Gen Psychiatry. 2001a Dec;58(12):1108-14.
67 Wehr TA. The durations of human melatonin secretion and sleep respond to changes in daylength (photoperiod). J Clin Endocrinol Metab. 1991 Dec;73(6):1276-80.

68 Rosenthal NE, Sack DA, Gillin JC, Lewy AJ, Goodwin FK, Davenport Y, et al. Seasonal affective disorder. A description of the syndrome and preliminary findings with light therapy. Arch Gen Psychiatry. 1984 Jan;41(1): 72-80.

69 Wehr TA. Bipolar mood cycles associated with lunar entrainment of a circadian rhythm. Transl Psychiatry. 2018 Aug;8(1):151.

70 Kripke DF, Elliott JA, Welsh DK, Youngstedt SD. Photoperiodic and circadian bifurcation theories of depression and mania. F1000 Res. 2015 May;4:107.

71 Schwartz PJ, Rosenthal NE, Turner EH, Drake CL, Liberty V, Wehr TA. Seasonal variation in core temperature regulation during sleep in patients with winter seasonal affective disorder. Biol Psychiatry. 1997 Jul;42(2):12231.

72 Schwartz PJ, Murphy DL, Wehr TA, GarciaBorreguero D, Oren DA, Moul DE, et al. Effects of meta-chlorophenylpiperazine infusions in patients with seasonal affective disorder and healthy control subjects. Diurnal responses and nocturnal regulatory mechanisms. Arch Gen Psychiatry. 1997 Apr;54(4): 375-85.

73 Schwartz PJ, Rosenthal NE, Wehr TA. Serotonin $1 \mathrm{~A}$ receptors, melatonin, and the proportional control thermostat in patients with winter depression. Arch Gen Psychiatry. 1998 Oct;55(10):897-903.

74 Schwartz PJ, Erk SD. Regulation of central dopamine-2 receptor sensitivity by a proportional control thermostat in humans. Psychiatry Res. 2004 Jun;127(1-2):19-26.

75 Cade BE, Gottlieb DJ, Lauderdale DS, Bennett DA, Buchman AS, Buxbaum SG, et al. Common variants in DRD2 are associated with sleep duration: the CARe consortium. Hum Mol Genet. 2016 Jan;25(1):167-79.

76 Blum ID, Zhu L, Moquin L, Kokoeva MV, Gratton A, Giros B, et al. A highly tunable dopaminergic oscillator generates ultradian rhythms of behavioral arousal. eLife. 2014 Dec;3:e05105.

77 Wehr TA. A "clock for all seasons" in the human brain. Prog Brain Res. 1996;111:321-42.
78 Monk TH, Buysse DJ, Welsh DK, Kennedy KS, Rose LR. A sleep diary and questionnaire study of naturally short sleepers. J Sleep Res. 2001 Sep;10(3):173-9.

79 Aeschbach D, Cajochen C, Landolt H, Borbély AA. Homeostatic sleep regulation in habitual short sleepers and long sleepers. Am J Physiol. 1996 Jan;270(1 Pt 2):R41-53.

80 Aeschbach D, Sher L, Postolache TT, Matthews JR, Jackson MA, Wehr TA. A longer biological night in long sleepers than in short sleepers. J Clin Endocrinol Metab. 2003 Jan; 88(1):26-30.

81 Jewett ME, Kronauer RE. Interactive mathematical models of subjective alertness and cognitive throughput in humans. J Biol Rhythms. 1999 Dec;14(6):588-97.

82 Boivin DB, Czeisler CA, Dijk DJ, Duffy JF, Folkard S, Minors DS, et al. Complex interaction of the sleep-wake cycle and circadian phase modulates mood in healthy subjects. Arch Gen Psychiatry. 1997 Feb;54(2):145-52.

83 Zimmerman M, Chelminski I, Young D, Dalrymple K, Martinez JH. A clinically useful self-report measure of the DSM-5 mixed features specifier of major depressive disorder. J Affect Disord. 2014 Oct;168:357-62.

84 Dodds TJ. Prescribed benzodiazepines and suicidal risk: a review of the literature. Prim Care Comp CNS Disord. 2017;19:16r02037.

85 Raja M, Azzoni A, Koukopoulos AE. Psychopharmacological treatment before suicide attempt among patients admitted to a psychiatric intensive care unit. J Affect Disord. 2009 Feb;113(1-2):37-44.

86 Bachhuber MA, Hennessy S, Cunningham $\mathrm{CO}$, Starrels JL. Increasing benzodiazepine prescriptions and overdose mortality in the United States, 1996-2013. Am J Public Health. 2016 Apr;106(4):686-8.

87 Cornell C. Fell on Black Days: Superunknown [album]. Santa Monica (CA): A\&M Records; 1994.

88 Wehr TA. Photoperiodism in humans and other primates: evidence and implications. J Biol Rhythms. 2001b Aug;16(4):348-64.

89 Mukherjee S, Coque L, Cao JL, Kumar J, Chakravarty S, Asaithamby A, et al. Knockdown of Clock in the ventral tegmental area through RNA interference results in a mixed state of mania and depression-like behavior. Biol Psychiatry. 2010 Sep;68(6):503-11.
Chris Cornell and the Seasonality of Suicide
Neuropsychobiology 2018/2019;78:38-47 DOI: $10.1159 / 000498868$ 